\title{
Giant Ocular Surface Squamous Neoplasia Wrapping Almost the Whole Cornea: A Case Report
}

\author{
Poonam Shrestha, Mukesh Pandey \\ Department of Ophthalmology, Nepal Eye Hospital, Tripureshwor, Kathmandu, Nepal \\ Corresponding author: \\ Poonam Shrestha, MBBS, MS \\ Department of Ophthalmology, Nepal Eye Hospital, Tripureshwor, Kathmandu, Nepal \\ Email: mepoonam120@gmail.com
}

Submitted : Jun 7, 2020

Accepted : July 22, 2020

\begin{abstract}
Ocular surface squamous neoplasia (OSSN) includes the dysplastic lesions involving the epithelium of conjunctiva and cornea with various clinical pictures. Histopathological examination of the excised tissue is the benchmark for diagnosis. Surgery, chemotherapy, immunotherapy are the various treatment modalities which in combination shows promising result. We present here a case of 83 years old female patient with history of fleshy mass covering the cornea and the patient was diagnosed clinically as ocular surface squamous neoplasia. Patient underwent surgical excision of the mass followed by cryotherapy. Histopathological examination revealed conjunctival intraepithelial neoplasia of grade 3. Six months after treatment the patient is completely tumor free with no recurrence.
\end{abstract}

Keywords: Conjunctival intraepithelial neoplasia, ocular surface squamous neoplasia

\section{INTRODUCTION}

$\mathrm{O}$ cular surface squamous neoplasia (OSSN) is a spectrum of pathology ranging from noninvasive conjunctival intraepithelial dysplasia (CIN) and cornea to invasive squamous cell carcinoma (SCC). ${ }^{1}$ The origin of OSSN is from limbal stem cells present in the interpalpebral region and involves the bulbar conjunctiva, the cornea, or both structures. ${ }^{2}$ The incidence of OSSN is $0.13-1.9 / 100,000$ population, and it primarily occurs in older males. ${ }^{3} \mathrm{CIN}$ includes varying grades of dysplasia, ranging from mild, moderate, severe dysplasia to carcinoma in situ. ${ }^{4}$ Risk factors for the development of OSSN are advanced age, male gender, ultraviolet radiation, human papilloma virus (HPV) infection, immunosuppression, and human immunodeficiency virus (HIV) infection. ${ }^{5}$
The modality for treatment of OSSN ranges from wide surgical excisions by "no-touch" technique, adjunctive cryotherapy, chemotherapy, immunotherapy. ${ }^{6}$ We report a case of OSSN involving almost the entire cornea in a female and HIV negative patient which is rather unusual. Literatures have shown OSSN are more common in males and in cases with HIV positive. The patient was successfully treated with no recurrence, after intact surgical removal and cryotherapy.

\section{CASE PRESENTATION}

A 83 years old female patient presented to the general out patient department of Nepal eye hospital with complaints of foreign body sensation, redness and diminution of vision in left eye since 1 year. She also noticed a mass in left eye which 
gradually increased in size ( Figure 1). There was no history of trauma or foreign body in the left eye and no history of any ocular surgery in the past. General and systemic examination were normal. On examination of left eye her vision was counting finger close to face (CFCF), slit lamp examination revealed grayish white gelatinous mass measuring about $8 \mathrm{~mm} \times 6 \mathrm{~mm}$ involving almost entire interpalpebral region of cornea. It appeared to be adherent to cornea and presence of feeder vessel was also seen. The details of anterior chamber, iris, pupil and lens was visible and grade III nuclear sclerosis was noted. Fundus evaluation after dilatation was normal. Intraocular pressure was measured with digital tonometry which was normal as applanation tonometry could not be performed as cornea was covered with mass. Ocular movements were full and free in all cardinal gaze. The right eye had grade II nuclear sclerosis. Preauricular and submandibular lymph nodes were not palpable. The patient was not positive for HIV. Left eye anterior segment OCT was normal (Figure 2). Clinical diagnosis of OSSN of the cornea was made. The patient was posted for a surgical excision of the mass and cryotherapy. Under all aseptic condition and after application of peribulbar anesthesia conjunctival peritomy of $4 \mathrm{~mm}$ clear margin around the lesion was done. The mass was excised in toto following "Shield's no touch technique" along the surgical plane, so the extent was well demarcated. The excised mass was sent for histopathological examination. Double freezethaw cryotherapy was applied with conical probe of $1 \mathrm{~mm}$ to the conjunctival edges and limbus. Ocular surface reconstruction was done with conjunctival auto graft. Postoperative treatment included topical application of steroid-antibiotic combination in tapering dose and artificial tears (Figure 3). Histopathology report showed severe dysplasia and intraepithelial mixed inflammatory cells suggestive of conjunctival intraepithelial neoplasia grade 3 . In 3 months follow up her vision had improved to 5/60 and on examination of cornea, it was clear with no signs of recurrence. She underwent cataract surgery after one month from last visit. After cataract surgery vision improved to 6/12 with no signs of recurrence of the lesion.

\section{DISCUSSION}

The term "Ocular surface squamous neoplasia (OSSN)" was first proposed by Lee and Hirst in 1995 to describe the spectrum of dysplasia, carcinoma in situ and squamous cell carcinoma of ocular surface. OSSN can be seen in all races and most commonly in countries closer to the equator where exposure to sunlight is more frequent. The risk factors are chronic inflammatory diseases of the ocular surface, exposure to ultraviolet light, increased p53 expression, HIV and HPV infection. ${ }^{7}$ The symptoms of OSSN includes as a growth of fleshy mass on the

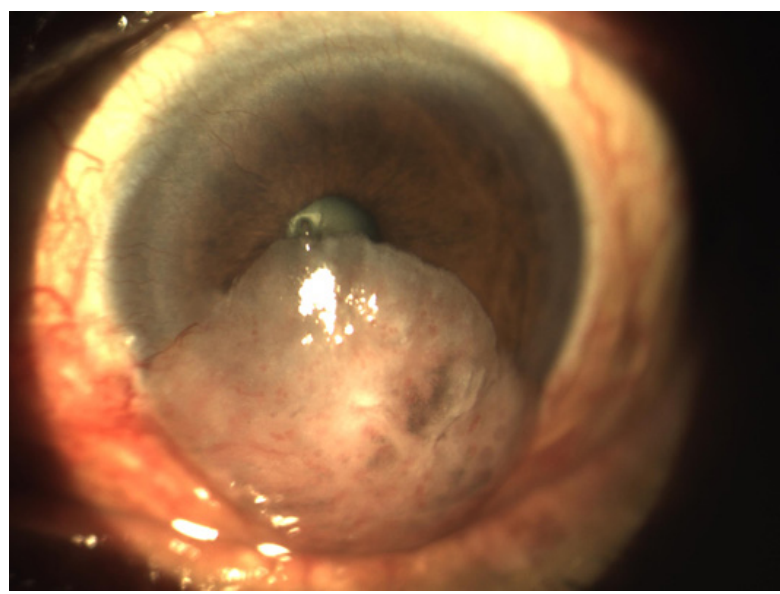

Fig 1. Pre-operative picture of the lesion showing gelatinous mass with feeder vessels
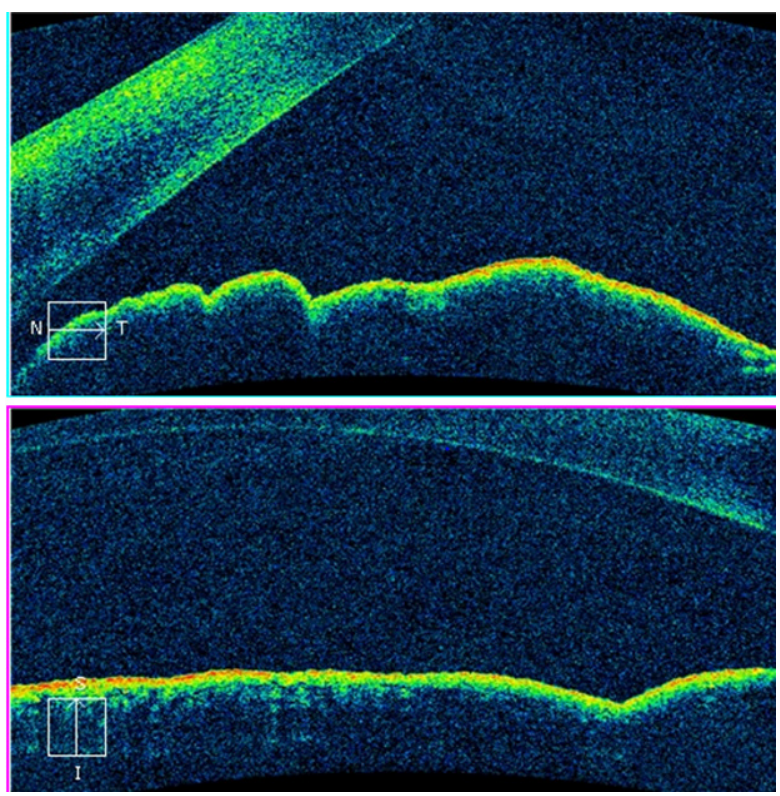

Fig 2. Anterior segment OCT of left eye showing no intraocular invasion

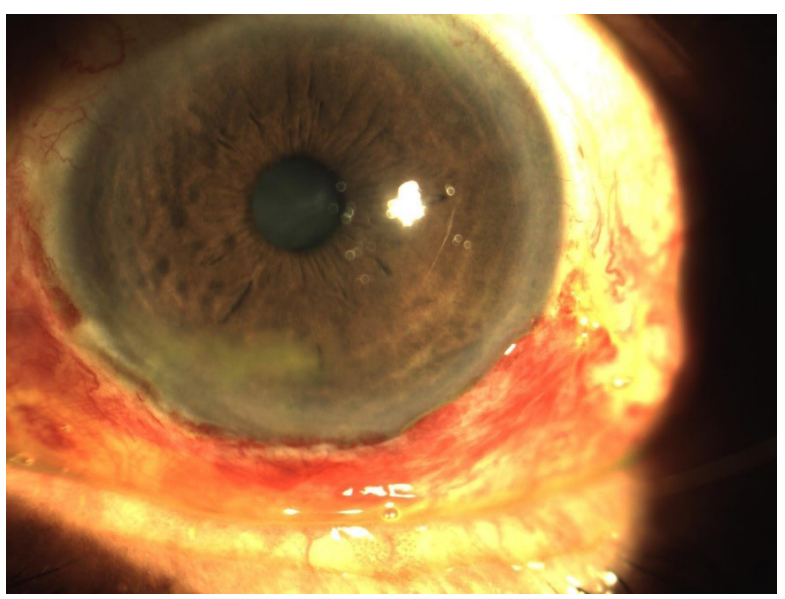

Fig 3. First post-operative day showing small corneal epithelial defect and graft in situ 
ocular surface, foreign body sensation, redness or irritation and rarely, decrease in vision which may be due to high astigmatism or after the involvement of visual axis. Many studies have shown that around $95 \%$ of OSSN cases originate in the limbus and often in the interpalpebral region. The reasons behind the involvement of interpalpebral includes factors like high ultraviolet exposure and mitotic rate, due to presence of transitional type epithelium..$^{8-9}$ Studies have also shown males are more prone to develop OSSN whereas we had female case and the involvement was in the interpalpebral region involving limbus as in other studies. In our case the patient had no history of HPV and HIV infection which are the risk factors for OSSN.

The common modality for the treatment of OSSN is surgical excision with "wide margin, no touch" technique. With this technique recurrences of the lesions are common which are dependent on the surgical margin involvement. Studies have found recurrence rate is $5 \%$ when the surgical margins are free in histopathology after excision and $53 \%$ when the surgical margins are involved. To reduce the recurrence adjunctive therapies like intra operative cryotherapy, brachytherapy, postoperative topical chemotherapy using mitomycin C, 5-fluro uracil and interferon alfa-2b are given. ${ }^{10} \mathrm{We}$ performed surgical excision of the lesion and cryotherapy was done to reduce the chances of recurrence and to avoid the need for adjunctive chemotherapy.

The histopathological report of our case showed conjunctival intraepithelial neoplasia grade III with free margins. Cryotherapy was also applied intra operatively so the patient was put on observation without post-operative topical chemotherapy. As topical chemotherapy has lot of side effects and patient was able to come for regular follow up so it was avoided. Our case had age related senile cataract which was present previously and not after the lesion excision so it may not be associated to ocular surface squamous neoplasia. At six month's post-surgical review, the patient was free from any clinical recurrence and improvement of vision was seen.

\section{CONCLUSION}

Though squamous lesions of the cornea and conjunctiva are uncommon, but early diagnosis and initiation of proper modality of treatment are key in prevention of visual loss and systemic morbidity and mortality. Adjunctive chemotherapy is not required in every case if regular follow up of patient can be done after surgical excision.

\section{CONFLICT OF INTEREST}

None declared.

\section{CONSENT}

Written consent was obtained from the patient for the publication of this case report and the images.

\section{REFERENCES}

1. Lee GA, Hirst LW. Ocular surface squamous neoplasia. Surv Ophthalmol. 1995;39(6):429-450

2. Mitchael T, Carol LK. Modern management of ocular surface squamous neoplasia. Expert Rev Ophthalmol. 2013;8(3):287-295.

3. Coroi MC, Rosca E, Mutiu $G$ et al. Squamous carcinoma of the conjunctiva. Rom J Morphol Embryol 2011;52 1 Suppl: 513-5.

4. Pizzarello LD, Jakobiec FA. Bowen's disease of the conjunctiva: a misnomer, IN: Jakobiec FA, editor. Ocular adnexal tumours. Birmingham, AL Aescullapius, 1978. p 553-71

5. Karcioglu ZA, Wagoner MD. Demographics, etiology and behavior of conjunctival squamous cell carcinoma in the 21st century. Ophthalmology 2009; 116: 2045-6.

6. Meel R, Dhiman R, Vanathi M et al. Clinicodemographic profile and treatment outcome in patients of ocular surface squamous neoplasia. Indian J Ophthalmol. 2017; 65:936-941.

7. Grossniklaus HE, Green WR, Luckenbach $M$ et al. Conjunctival lesions in adults. A clinical and histopathological review. Cornea 1987; 6:78-116.

8. Papaioannou IT, Melachrinou MP, Drimtzias EG et al. Corneal-conjunctival squamous cell carcinoma. Cornea 2008; 27:957-8

9. Tunc M, Char DH, Crawford B et al. Intraepithelial and invasive squamous cell carcinoma of the conjunctiva: Analysis of 60 cases. Br J Ophthalmol 1999; 83:98-103.

10. Erie JC, Campbell RJ, Liesegang TJ. Conjunctival and corneal intraepithelial and invasive neoplasia. Ophthalmology 1986; 93:176-83. 